\title{
Lesión de Nora. Una entidad poco frecuente $y$ de tratamiento discutible
}

\author{
M. A. Fontestad Utrillas ${ }^{(1)}$, L. Aguilella Fernández ${ }^{(2)}$ \\ Hospital Universitario La Ribera. Alzira (Valencia). Servicio de Cirugía Ortopédica y Traumatología \\ (1) MÉdico Residente de $5^{\circ}$ AÑo \\ (2) MÉdico AdJunto
}

Correspondencia:

Dra. Ma Amparo Fontestad Utrillas

Servicio de Cirugía Ortopédica y Traumatología. Hospital Universitario La Ribera

Carretera de Corbera ,Km. 1

46600 Alzira, Valencia (España)

Teléfono: 962458100

Fax: 962458100

e-mail: amparofontestad@gmail.com

\begin{abstract}
La lesión de Nora se incluye en un conjunto de lesiones benignas caracterizadas por una proliferación anómala de tejido óseo y fibroso asociado a una reacción perióstica reactiva. Debido a su aspecto inicial, esta lesión puede ser confundida con una lesión maligna. Es frecuente realizar un diagnóstico incorrecto de esta entidad y, en consecuencia, un tratamiento improcedente. Se presenta el caso de una lesión de Nora que fue inicialmente diagnosticada de miositis osificante.
\end{abstract}

Palabras clave: Lesión de Nora, miositis osificante, reacción perióstica.
The Nora's lesion is included inside a benign lesion's group characterized by an abnormal proliferation of osseous and fibrous tissue associated with a parosteal reaction. Due to its initial aspect, this lesion can be mistaken for a malignant lesion. Not infrequently, an incorrect diagnosis of this entity is made and, subsequently, an inappropriate treatment is carried out. We report a Nora's lesion case, which was initially diagnosed as myositis ossificans.

Key words: Nora's lesion, myositis ossificans, parosteal reaction.

\section{INTRODUCCIÓN}

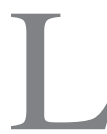

os tumores óseos primarios de la mano son habitualmente benignos. La denominada lesión de Nora es también una lesión benigna, aunque su aspecto inicial puede confundirse con el de una maligna. Esta lesión se caracteriza por una proliferación exofítica de tejido óseo y fibroso, generalmente de aparición en falanges ${ }^{1}$. Desde que se describió en 1983, sólo se han descrito unos 166 casos aproximadamente ${ }^{2}$. El diagnóstico es básicamente radiológico, siendo discutible la necesidad de una biopsia preope- ratoria. El interés en conocer este tipo de lesión radica en que, por sus manifestaciones clínicas iniciales, puede ser incorrectamente tratada dada su similitud con otras entidades. A continuación se presenta un caso de lesión de Nora, inicialmente diagnosticado de miositis osificante.

\section{CASO CLÍNICO}

Mujer de 46 años, profesora de un instrumento de cuerda, que refería la aparición espontánea, 3 meses antes, de una tumoración dolo- 


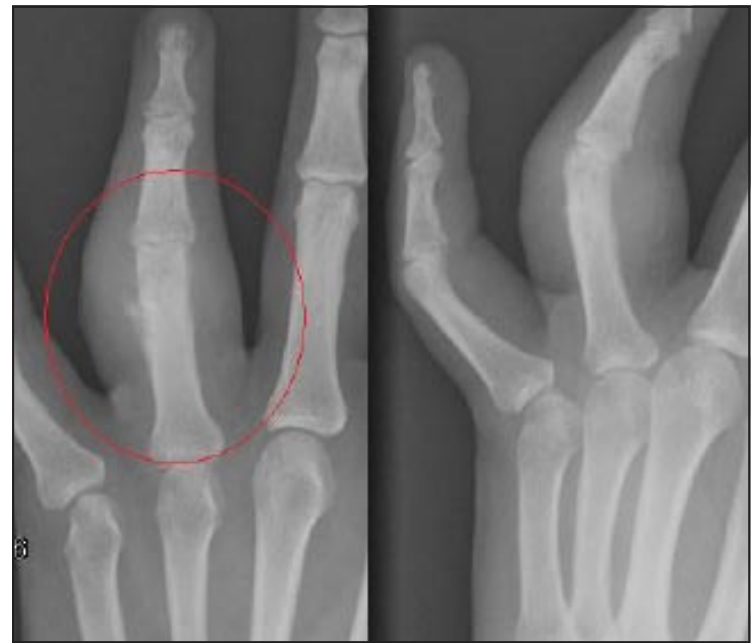

Figura 1: Radiografía simple: reacción perióstica cortical en la falange media.

rosa y limitante de la movilidad en la falange proximal del cuarto dedo de la mano derecha. Un mes antes de acudir a nuestra consulta, se le había efectuado una resección-biopsia en otro centro, siendo diagnosticada, según el informe de la anatomía patológica, de miositis osificante o heterotópica. La paciente solicitó una nueva valoración dada la persistencia del dolor y la acusada limitación funcional que le impedía desempeñar su trabajo.

En la exploración presentaba tumefacción difusa y signos inflamatorios en el cuarto dedo, con limitación de la flexo-extensión. La radiografía simple mostraba una reacción perióstica cortical en la falange media (Figura 1). Dada la incertidumbre diagnóstica, se solicitó una resonancia magnética, que el Servicio de Radiología decidió completar con una TAC. La lesión fue descrita como una reacción perióstica cortical de contenido exofítico con componente de partes blandas dependiente del periostio, acompañada de engrosamiento de la polea A2 y la vaina del tendón flexor (Figura 2). Ante estos hallazgos, el diagnóstico diferencial se planteó entre las lesiones de superficie ósea, sugiriéndose la lesión de Nora como el diagnóstico más apropiado.

A partir de este diagnóstico, dada la alta tasa de recurrencias tras la escisión quirúrgica en la fase activa de este tipo de lesión y que la sintomatología de la paciente iba en disminución, se decidió mantener en observación a la paciente con tratamiento antiinflamatorio. A los cuatro

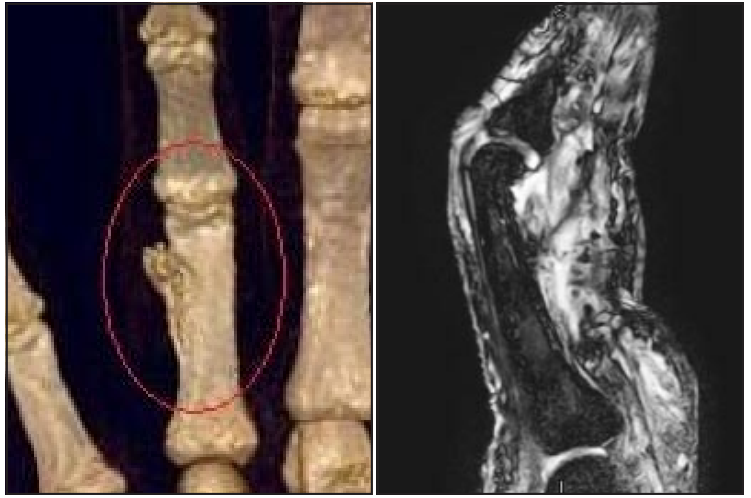

Figura 2: TAC y RM. Reacción perióstica con componente de partes blandas.

meses, la paciente presentaba una importante mejoría clínica. A los siete meses, la movilidad era prácticamente completa, con una limitación de 5 grados de extensión no teniendo dificultad para llevar a cabo su trabajo habitual. La única molestia que refería era la presencia de una prominencia ósea a nivel volar de la falange proximal que en la radiografía simple se mostraba sin

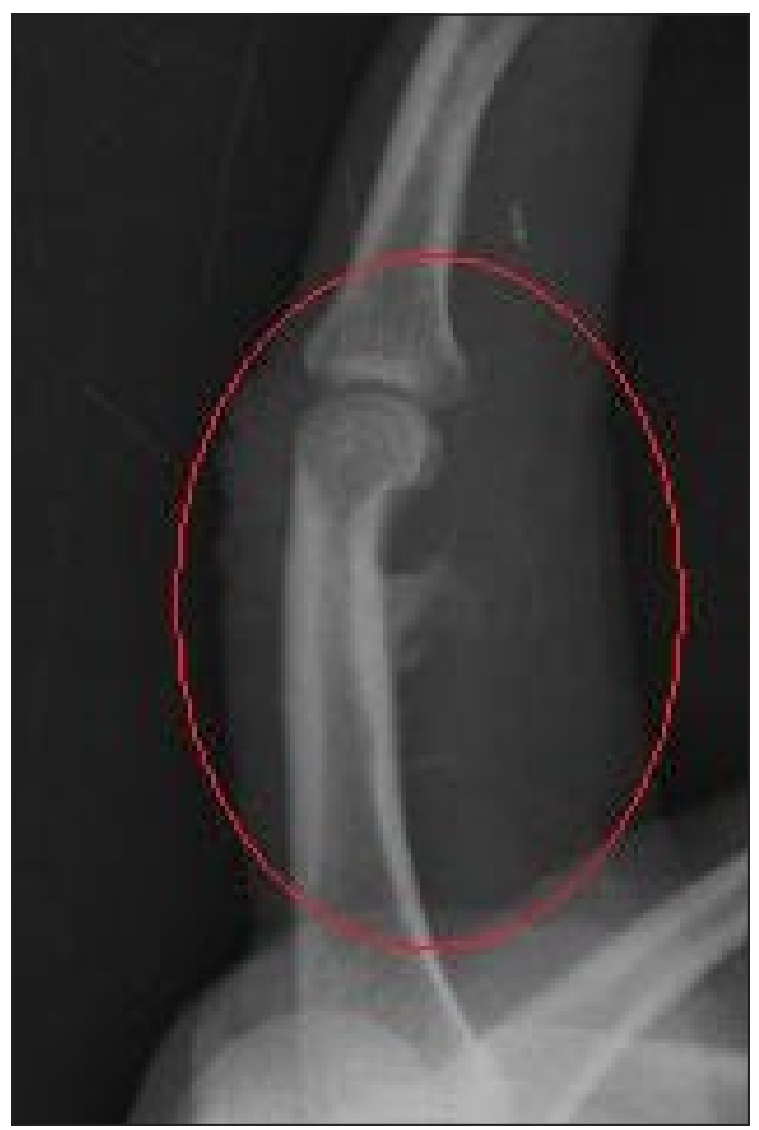

Figura 3: Prominencia ósea volar. 
reacción perióstica (Figura 3). Dada la inactividad de les lesión y que resultaba molesta para la paciente, se realizó la exéresis de la misma que el Servicio de Patología describía como una simple hipertrofia ósea. Por tanto, la evolución clínica y radiológica observada confirmaba el diagnóstico de lesión de Nora.

\section{DISCUSIÓN}

La lesión de Nora o BPOP (Bizarre Parosteal Ostechondromatous Proliferation), fue descrita en $1983^{3}$ como una proliferación benigna de tejido óseo y fibroso, que guarda similitud con la periostitis florida reactiva (PFR) y la exótosis subungueal (Turret exostosis). La PFR se considera la forma más inmadura mientras que la exostosis subungueal sería la fase más evolucionada de este espectro de lesiones estando relacionada ésta última con la existencia de un traumatismo previo ${ }^{4,5}$. Aparece más frecuentemente en adultos jóvenes y particularmente en las manos donde suele asentar en las falanges ${ }^{6}$.

La lesión de Nora suele manifestarse como una masa dolorosa de crecimiento lento que se acompaña de inflamación y rigidez articular. En los estudios de imagen, se muestra como una tumoración ósea pediculada, con márgenes bien delimitados. Asienta sobre la superficie ósea sin alterar la cortical y la medular ${ }^{3,6}$.

El diagnóstico diferencial se debe realizar con lesiones benignas como la exóstosis postraumática, el condroma periostal, el osteocondroma y la miositis osificante y con lesiones malignas como el osteosarcoma y el condrosarcoma ${ }^{2,4-7}$ en base a la historia clínica, la radiología y la localización de la lesión aunque el mejor método para realizar el diagnóstico diferencia es el estudio anatomopatológico ${ }^{2}$.

La patogenia de este tipo de lesión es controvertida. Se especula que puede tratarse de una lesión reactiva a un traumatismo previo, si bien la mayoría de los casos no están relacionados con éste ${ }^{2} \mathrm{o}$ de una lesión neoplásica, ya que en ocasiones se ha detectado una alteración cromosómica tipo $\mathrm{t}(1 ; 17)$ asociada $^{1,8}$.

El diagnóstico de la lesión de Nora es básicamente radiológico. Una vez sospechado, no es recomendable efectuar ni una biopsia ni una exéresis de la lesión, dado que evoluciona espontáneamente a la resolución de los síntomas. De hecho, realizar un gesto quirúrgico en la fase sintomática de la lesión, está asociado a una reactivación de la misma ${ }^{6,7}$. La tasa de recidiva después de la cirugía es de un $50 \%{ }^{2}$.

\section{BIBLIOGRAFÍA}

1. Zambrano E, Nosé V, PérezAtayde AR, Gebhardt M, Hresko MT, Kleinman P, et al. Distinct chromosomal rearrangement in subungueal (Dupuytren) exostosis and bizarre parosteal osteochondromatous proliferation (Nora's lesion). Am J Surg Pathol, 2004; 28: 1033-9.

2. Flint JH, McKay PL. Bizarre parosteal osteochondromatous proliferation and periosteal chondroma: a comparative report an review of the literature. J Hand Surg Am, 2007; 32: 893-8.

3. Nora FE, Dahlin DC, Beaubout JW. Bizarre parosteal osteo- chondromatous proliferation of the tubular bones of the hands and feet. Am J Surg Pathol, 1983; 7: 245-50.

4. Rubin JA, Steinberg DR. Turret exostosis of the metacarpal: A case report. J Hand Surg Am, 1996; 21: 296-8.

5. Amillo S, Romero LM. Exóstosis postraumática del quinto metacarpiano: diagnóstico diferencial con osteocondroma. Rev Iberoam Cir Mano, 2010; 38: 8-10.

6. Menesses MF, Unnik K, Swee RG. Bizarre parosteal osteochondromatous proliferation of bone (Nora's lesion). Am J Surg Pathol, 1993; 17: 691-7.

7. Dhont E, Ondenhoven L Khan S, Kroon HM, Hogendoom PC, Nieborg A, et al. Nora's lesion, a distinct radiological entity? Skeletal Radiol, 2006; 35: 497-502.

8. Nilsson M. Domanski HA, Mertens F, Mandahl N. Molecular cytogenetic characterization of recurrent translocation breakpoints in bizarre parosteal osteochondromatous proliferation (Nora's lesion). Hum Pathol, 2004; 35: 1063-9. 